\title{
Anonimato e segredo na reprodução humana com participação de doador: mudanças em perspectivas'
}

\section{Anonymity and secrecy in human reproduction with donor participation: shifts in perspectives}

\section{Rosana Machin}

Universidade de São Paulo. Faculdade de Medicina. Departamento

de Medicina Preventiva. São Paulo, SP, Brasil.

E-mail: rmachinळusp.br

\section{Correspondência}

Av. Doutor Arnaldo, 455, 2 andar, Sala 222।. São Paulo, SP, Brasil. CEP 01246-903.

\begin{abstract}
Resumo
As tecnologias reprodutivas, ao separar a sexualidade da reprodução, interferiram não somente nas relações entre os sexos, mas também nas relações de filiação, possibilitando o surgimento de configurações familiares decorrentes do acesso a material genético de terceiros (doadores de óvulos, sêmen ou embrião). O segredo e o anonimato que sempre envolveram os doadores de gametas têm sido desafiados. Nos últimos vinte anos, diversos países alteraram sua legislação adotando a identidade aberta do doador de material genético. A possibilidade de conhecer e ter acesso a esta identidade (chegando à maioridade) ou mesmo a busca por meios irmãos pode ser uma realidade em muitos países para crianças nascidas por meio do acesso à tecnologia reprodutiva. $\mathrm{O}$ artigo enfatiza a questão do segredo e do anonimato envolvendo o uso de material genético de terceiros em tecnologias reprodutivas. A discussão é explorada por meio do debate ocorrido no Reino Unido relativo à abolição do anonimato e suas implicações sob a perspectiva dos doadores, dos casais demandantes e da criança concebida. 0 estudo reflete ainda sobre as concepções de família envolvidas nessa discussão.

Palavras-chave: Tecnologia Reprodutiva; Doador de Sêmen; Privacidade; Família.
\end{abstract}

1 Agradeço ao suporte recebido do CNPq (Conselho Nacional de Desenvolvimento Científico e Tecnológico) pelo meio de auxílio à pesquisa e bolsa de pós-doutoramento, e ao The Centre for Family Research (Cambridge University) pelo apoio durante o período no qual estive como professora visitante. 


\section{Abstract}

Reproductive technologies, when separating sexuality from reproduction, interfered not only in the relationships between the sexes, but also in the relationships of filiation, enabling the emergence of family settings due to the access to genetic material from others (egg, semen or embryo donors). The secrecy and anonymity that have always involved gamete donors have been challenged. In the last twenty years, various countries changed their legislation, adopting the policy of open identity of the donor of the genetic material. The possibility to know and have access to this identity (when reaching adulthood) or even the search for half-brothers can be a reality in many countries for children born through access to reproductive technology. The article emphasizes the matter of secrecy and anonymity involving the use of genetic material from others in reproductive technologies. The argument is set up through the debate in the United Kingdom concerning the abolition of the anonymity and its implications under the perspective of donors, claimant couples and the child. The study also reflects on the conceptions of family involved in this debate. Keywords: Reproductive Technology; Semen Donor; Privacy; Family.

\section{Introdução}

A possibilidade de conhecer a identidade do doador de material genético ao chegar à maioridade é uma realidade em vários países nas situações em que o acesso à tecnologia reprodutiva ${ }^{2}$ (TR) com uso de material genético de terceiros possibilita o nascimento de um bebê. Nesse contexto, países como a Suécia (1985), Suíça (1985), Áustria (1992), Nova Zelândia (1994), alguns estados da Austrália (1995), Holanda (2004), Noruega (2005), Reino Unido (2005), Alemanha (2006) e Canadá (2011, no estado de British Columbia) já aboliram práticas de anonimato nas situações de doação de material genético (open-identity gamete donation). Islândia, Bélgica e Estados Unidos admitem práticas com anonimato e sem anonimato. Em 2006, foi lançada a diretiva da União Europeia (The European Tissue Directive) estipulando a manutenção dos registros sobre as práticas realizadas com o uso de material genético por pelo menos trinta anos (Frith, 2001; Turkmendag, 2012).

A abolição das práticas de anonimato está baseada na consideração do bem estar das crianças nascidas, e há atualmente um intenso debate sobre as consequências negativas de se omitirem as informações aos envolvidos. Destaca-se igualmente o crescimento da discussão em redes sociais criadas por filhos e mães de crianças gestadas por meio de TR, visando localizar os doadores do material genético (seus pais biológicos), especialmente nos Estados Unidos, país onde vigora um significativo mercado reprodutivo por meio da disponibilidade de compra/venda de sêmen e óvulos 3 .

Em 1995, Salem observava os efeitos e diferenciações relativas ao princípio do anonimato na inseminação artificial com uso de doador enfatizando

2 Tecnologias reprodutivas (TR) designam tecnologias médicas usadas para obter a gestação em contextos nos quais ela não pode ser obtida por relações sexuais. Algumas tecnologias incluem, por exemplo, estimulação da ovulação, fertilização in vitro (FIV), inseminação com doador (ID), injeção intracitoplasmática de espermatozoide (ICSI). Similarmente o termo "reprodução assistida" (RA) é usado.

3 A esse respeito há o blog AnonymousUS.org (Disponível em: <http://anonymousus.org/>. Acesso em: 20 abr. 2015) - realizado por uma jovem nascida de procedimento de reprodução assistida e que objetiva discutir a fragmentação familiar e uso dessas tecnologias, e o site denominado The Donor Sibling Registry (DSR - https://www.donorsiblingregistry.com), uma base de registro norte-americana, fundada em 2000 por Wendy Kramer, voltada ao registro, conexão e suporte a famílias criadas por uso de doadores (gametas). Com relação a este último alguns artigos se dedicam ao tema: Jadva et al. (2010), Beeson et al. (2011) e Scheib e Ruby (2008). 
o contexto de tensões presentes nesse campo. Naquela época tal princípio era praticamente adotado pela maioria dos países no campo da reprodução assistida (RA). Assim, nas transações que envolviam o uso de material genético de terceiros havia a imposição do anonimato entre doadores e receptores. A autora ainda chamava a atenção para o fato de que essas práticas podiam ser percebidas também em outros contextos, que envolviam doações como as relativas à adoção, quando a mãe que doava seu filho também permanecia em segredo (Salem, 1995; Fonseca, 2010).

As explicações sociais utilizadas para justificar a manutenção ou supressão do anonimato ou do segredo envolvem contextos distintos, como a circulação de crianças para adoção ou mesmo o uso de células germinativas, indicando que essa situação revela práticas e valores mais amplos relacionados às nossas representações sobre parentesco, família e filiação ${ }^{4}$.

Quando usamos o termo "segredo" aludimos disposições dos envolvidos (casal ou pessoa solteira), que fazem uso da técnica e daquele indivíduo que figura como doador, de preservar a realização da prática - uso de inseminação artificial ou fertilização in vitro e o ato de doação de sêmen. 0 termo "anonimato" indica uma política adotada com relação ao doador do material genético pela qual há uma ocultação mútua da identidade das pessoas envolvidas no processo, sendo somente o médico o detentor destas informações. Assim, segredo se refere à ocultação da própria existência de um doador, enquanto o anonimato esconde sua identidade (Salem, 1995; Novaes, 1989; Fonseca, 2010, 2011).

Segredo e anonimato envolvem concepções e práticas interconectadas de ocultação deliberada e de partilha. Apesar dos termos expressarem diferentes inclusões e exclusões, envolvem personagens distintos. Nessas situações podemos falar do doador que não pretende ser identificado e podemos falar do casal que busca o serviço de saúde e não quer que sua situação seja conhecida. O médico que guarda "todas" as informações relativas ao processo e figura como aquele que pode ligar a identidade dos sujeitos envolvidos; o casal (heterossexual ou homossexual) ou pessoa solteira/separada ou viúva que faz uso das técnicas; o(a) provedor(a) do material genético; o banco de sêmen que forneceu o material genético. Há uma personagem que, até anteriormente, era a grande ausente do debate sobre as práticas - a criança concebida por meio de TR5.

Turkmendag et al. (2008) observam que as práticas relativas ao uso de material genético doado sempre haviam sido cercadas de segredo. Até os anos 1970, era prática entre médicos realizar a inseminação usando mais de um doador por ciclo, objetivando deliberadamente confundir a paternidade, além de realizarem a destruição dos registros referentes aos pais envolvidos. Assim, se até meados dos anos 1990 a prática de segredo e anonimato fazia parte de uma norma amplamente praticada, o que fez essa posição ser alterada?

O movimento de crescente questionamento do anonimato está baseado na asserção do direito da criança nascida de saber sobre sua origem biológica por meio do estabelecimento de paralelos entre os direitos de crianças adotadas com aquelas concebidas por meio do acesso a material genético de terceiros (Cameron et al., 2010; Turkmendag et al., 2008). Partindo desse contexto, este artigo objetiva analisar as concepções e práticas envolvidas com o uso de material genético de terceiros em procedimentos relativos às TRs e os princípios de segredo e anonimato através do debate no Reino Unido ${ }^{6}$,

\footnotetext{
4 Mencionar nesse contexto “nossas representações" significa considerar o universo cultural compreendido na sociedade ocidental moderna, ainda que esse referencial possa em algumas situações remeter a determinadas camadas sociais (médias e altas).

5 A esse respeito, Golombok S., "Research on lesbian and gay parenting: a historical perspective across 30 years". Mimeo, 2006.

60 artigo tem por referência a doação e uso de sêmen considerada prática mais antiga e que envolve processos significativamente diferentes e menos onerosos do que aqueles relacionados à doação de óvulos. Enquanto o sêmen é obtido por meio de masturbação, a obtenção de óvulos se faz por meio do uso de medicação (visando estimular a ovulação) e procedimento cirúrgico (Mohr, 2014; Almeling, 2009). Registro ainda a existência de tratamento diferencial com relação às doações masculinas e femininas e os princípios de anonimato envolvidos, mas cuja discussão escapa às intenções deste artigo. A esse respeito ver Salem (1995).
} 
realizado previamente à definição legal da abolição do anonimato. 0 debate recai sobre este país por representar um lugar estratégico quanto às práticas e preceitos ético-legais do campo das TR. Seu lugar de relevância ocorre por ter sido responsável pelo nascimento do primeiro bebê de proveta e por ter estabelecido importantes referências éticas relativas ao uso e desenvolvimento dessas tecnologias, sendo um parâmetro para diversos países. Para efeito desta discussão, o contexto de outros países será articulado ao debate.

Na primeira parte do texto contextualizamos os termos anonimato e segredo envolvidos no campo em discussão, situando suas origens históricas e práticas legais. Na segunda parte, abordamos as argumentações envolvidas no debate sobre a abolição do anonimato. Na parte final, discutimos as implicações desse debate com relação à compreensão sobre família e a situação existente nesse campo no Brasil.

\section{Discussão - segredo e anonimato envolvidos na concepção}

O uso de inseminação artificial com sêmen doado é uma prática que remonta ao século dezenove na Europa e Estados Unidos, contudo era realizado de forma sigilosa. O procedimento vai ganhando novos contornos com a emergência dos bancos de sêmen a partir do século XX e se institucionaliza como prática na maioria dos países ocidentais sob a égide do anonimato dos doadores envolvidos (Beeson et al., 2011; Daniels, 2006; Daniels, Haimes, 1998; Schmidt, Moore, 1998). De 1986 a 1987, por exemplo, cerca de 30 mil nascimentos anuais nos Estados Unidos foram resultantes do uso de inseminação artificial com doador (ID). Estimativas recentes mencionam a cifra de 60 mil nascimentos por ano (Beeson et al., 2011; Johns, 2013)7 . A prática pode ser usada em diferentes contextos, o que acaba por guardar particularidades quanto às experiências e dilemas envolvidos. 0 uso de ID foi primeiramente desen- volvido entre casais heterossexuais e em muitos países ainda por força de lei continua circunscrito a esses casos. Contudo, sua prática tem crescido entre mulheres solteiras e casais de mesmo sexo (Lasker, 1998). Importa considerar que a prática relativa à doação de sêmen apresenta particularidades quanto à remuneração envolvida no processo. Ela pode ser considerada como uma atitude altruísta, realizada para colaborar com aqueles que têm dificuldades para conceber e, além disso, os doadores recebem compensação relativa às despesas, que podem ter tido quanto ao deslocamento e alimentação, caso do Reino Unido. No Brasil os doadores são proibidos de receber qualquer tipo de ajuda, para não configurar qualquer caráter comercial. Já os Estados Unidos se destacam por representar um mercado amplo de fornecimento de material genético (sêmen e óvulos), em que os doadores são remunerados ${ }^{8}$.

Alguns dos receios reportados pela literatura dizem respeito a incertezas quanto às características e identidade do doador. Há considerável ansiedade em muitos casais quanto à possível semelhança do doador com as características do marido, já que na maioria dos casos busca-se um doador objetivando que a filiação seja reconhecida como daquele casal, ocultando a prática (Lasker, 1998).

Haimes (1998), considerando uma breve história da prática de inseminação no Reino Unido de 1945 a 1973, menciona diferentes percepções sobre a pessoa gerada a partir do uso da técnica. Havia o receio do estigma de ilegitimidade quando se associava a pratica à ideia de adultério levando alguns especialistas legais a recomendar a criminalização da prática. Em 1958, uma comissão governamental expressa suas preocupações quanto à abertura de informação à criança com incertezas a respeito de seu desenvolvimento e recomendam que a prática seja desencorajada. De acordo com Haimes (1998) e Snowden e Snowden (1998), estudos nos anos 1970 mencionam preocupação com os interesses da criança, mas estes eram considerados menos

7 De acordo com Volkman (2012), desde a II Grande Guerra até 1995, cerca de um milhão de bebês nasceram por meio do uso de material genético de terceiros via bancos de sêmen.

8 Os bancos de sêmen trabalham com a demanda do consumidor e valorizam seu potencial para agregar valor ao material que comercializam, criando todo um imaginário que articula as possiblidades da ciência em selecionar os doadores mais adequados para poder proporcionar o "melhor bebê" (Daniels, 2006). 
importantes do que os envolvidos na permanência do segredo quanto à infertilidade do pai social. As práticas nesse período eram realizadas sem que houvesse um registro ou regulação oficial (Frith, 2001; Turkmendag et al., 2008). A criança nascida dessa prática era tecnicamente percebida como ilegítima e o doador era considerado o pai legal, apesar de na prática o marido da mulher que concebia constar da certidão de nascimento como o pai de fato. A ausência de aceitação social e legal reforçava o interesse por manter a prática em sigilo protegendo os adultos envolvidos (pais, doador e equipe médica).

O nascimento de Louise Brown em 1978, o primeiro bebê de proveta no Reino Unido resultante de uma fertilização in vitro, desencadeou um debate sobre o reconhecimento legal de novas práticas tecnológicas no campo da reprodução. 0 relatório Warnock (1984), resultante de um comitê criado para definir preceitos éticos e legais associados com a reprodução assistida, propõe que as crianças nascidas a partir de doação de material genético sejam definidas como legítimas, e o doador não deve ter direitos ou responsabilidades parentais (Turkmendag et al., 2008). Essa recomendação reforçava o princípio do anonimato e encorajava a doação e proteção da privacidade familiar.

Nos anos 1980, este debate se estendeu para além da esfera médica, havendo um crescente envolvimento social e de parlamentares em vários países resultando no estabelecimento de algumas recomendações e resoluções quanto à prática (Haimes, 1998).

Estudos realizados nos anos 1990 revelavam que a prática do uso de sêmen de doador na concepção era cercada de sigilo e os casais não informavam e não pretendiam revelar aos filhos concebidos por inseminação sobre sua origem genética. Daniels (et al., 2009), em estudo de acompanhamento realizado em duas fases (com 14 anos de diferença entre uma e outra) com 57 famílias da Nova Zelândia, revelou que $41 \%$ deles na Fase 1 concordavam em falar sobre a concepção com a criança e 59\% pretendiam não falar; na fase 2 houve pouca mudança nessas posições com um acréscimo de $53 \%$ entre aqueles que haviam falado. Algumas famílias mencionaram que sempre tiveram a intenção de falar e pretendiam buscar assistência para saber como fazê-lo. Certamente, pretender falar é diferente de contar e vários estudos apontam as dificuldades envolvidas nessa decisão (Snowden; Snowden, 1998; Readings et al., 2011; Söderstrom-Anttila et al., 2010; Beeson et al., 2011).

A postura de não abrir informações sobre esse processo, em regra, está relacionada ao estigma que cerca a infertilidade masculina. 0 desejo de proteger a criança e também a família tem sido dado como uma justificativa para essa informação permanecer em segredo (Beeson et al., 2011; Stevens et al., 2003; Söderström-Anttila et al., 2010). Questões relativas a revelar a informação sobre a concepção são indicativas da compreensão cultural do significado social dos relacionamentos criados e mantidos, ou seja, que vínculos são percebidos como família e parentesco, e que peso se atribui a eles. Para casais heterossexuais nos quais o homem é infértil, a inseminação com doador oferece a possibilidade de se ter um filho por meio de gestação e nascimento que pode ser apresentado como aparentemente tradicional. Ambos os parceiros podem viver a experiência da gestação sem ter de revelar a infertilidade masculina e há um vínculo biogenético do bebê com um dos parceiros (Lasker, 1998). Diferentemente, por exemplo, nos casos em que se opta pela adoção, pois a possibilidade do "segredo" sobre o processo torna-se mais difícil já que a chegada da criança não foi acompanhada de um processo de gestar percebido por parentes e amigos. Nesse caso, há o risco da situação ser percebida de alguma forma pela criança. Igualmente, mulheres solteiras ou casais de mesmo sexo, por representarem uma situação não reprodutiva ao optarem pela gestação por meio do uso de TR, em geral se deparam com a necessidade de ter que explicar para a criança a ausência de uma figura paterna ou materna.

Se para os médicos envolvidos nos tratamentos voltados à obtenção de um bebê por meio das TRs o nascimento de um bebê sadio pode indicar o fim de um processo, para as famílias envolvidas significa o começo de uma trajetória, que muitas vezes pode trazer incertezas e dúvidas quanto a como lidar com as informações sobre os eventos que tomaram parte para a chegada daquele novo ser. A orientação inicial que muitos profissionais de saúde transmitiam aos casais até os anos 1980 era não falar sobre o 
processo. No entanto, um clima de abertura emerge a partir de meados dos anos $2000^{9}$.

Pode-se afirmar que vários estudos já mencionavam efeitos negativos de se manter o segredo sobre a concepção (Readings et al., 2011). Segundo Stevens et al. (2003), manter segredo sobre uma criança concebida via ID cria uma carga que pode afetar o relacionamento familiar, porque há algo que não pode ser tocado, falado. Teme-se que alguém de fora ou alguma circunstância revele o que deve ser mantido em segredo. Ademais, abrir essa informação se torna mais difícil se esta ocorre de forma tardia ou na vida adulta.

Haimes (1998) reporta a existência de práticas nos anos 1980 visando aproximar crianças/jovens concebidos via ID de doadores. Em 1982, foi fundado Donor Offspring nos Estados Unidos por Candace Turner, que havia sido concebida por ID em 1948. Tendo dificuldade de descobrir suas origens genéticas por meio do acesso a médicos, ela iniciou uma campanha pelo direito dos concebidos via ID saberem sobre suas origens. Um artigo publicado no The New York Times Magazine em 1995 apresenta vários casos de concebidos via ID procurando por informações e falando sobre seus sentimentos quanto ao processo (Orenstein, 1995).

Em certo sentido, a voz e os sentimentos do concebido via ID tinham estado muitas vezes ausente desses debates. Assim, inicialmente foram representados não como indivíduos, mas como resultado de um procedimento. Posteriormente, passam a ser vistos como uma criança inserida numa rede de relacionamentos, o que possibilitou seu reconhecimento como sujeito a ter direitos de informações sobre sua concepção.

\section{A abolição do anonimato: os direitos da criança concebida}

A Suécia foi o primeiro país a abolir o anonimato relativo ao doador de material genético, em 1985.
Posteriormente, vários países passaram a alterar sua legislação com respeito ao uso de doador, banindo os processos que envolviam anonimato, alegando como razão para fazê-lo o bem-estar da criança concebida por estes meios e seu direito em saber a identidade do doador.

A noção de que o segredo em torno desse tipo de concepção era a melhor opção foi sendo enfraquecida ao longo do tempo. Alguns fatores contribuíram para essa situação. Inicialmente, estudos enfatizam os danos às famílias decorrentes da manutenção do segredo influenciando a criação de comitês voltados à discussão e estabelecimento de recomendações legais e éticas (Blyth et al., 2004; Sorosky et al., 1984; Karpel, 1980). Outro aspecto a ser destacado é a introdução (na legislação de diversos países) da proteção à figura do doador de qualquer responsabilidade financeira ou legal relativa às crianças resultantes de sua doação, que pode ser interpretada como um estímulo à realização da prática (Blyth et al., 2004). Também se menciona o surgimento de grupos de apoio como o Donor Conception Support Group of Australia Inc. (1997) e DI Network ${ }^{10}$, que são formados por pessoas que fizeram uso da prática e visam compartilhar suas experiências e informações com as crianças nascidas na Austrália e no Reino Unido, respectivamente.

No entanto, apesar desse suporte, estudos traziam evidências de que os pais ainda não se mostravam abertos a falar para suas crianças sobre o contexto de sua concepção. Assim, casais heterossexuais têm se mostrado os mais avessos a abrir a informação aos filhos concebidos por meio de ID (Stevens et al., 2003). Nesse caso, a dificuldade já mencionada quanto à infertilidade masculina e especialmente o fato de que falar sobre a verdadeira concepção significa desmontar e desconstruir uma "verdade" que pode haver sido previamente dada. Nesses casos, a literatura menciona sentimentos de confusão e agressividade dos filhos, em especial,

\footnotetext{
9 Em 2007, The Human Fertilization and Embriology Authority (http://www.hfea.gov.uk/3465.html), autoridade responsável pela regulação dos processos de TR no Reino Unido, menciona em seu guia sobre código de conduta a orientação aos profissionais que estes abordem com os pais a necessidade de informar a criança sobre sua origem. Em 2004, a American Society of Reproductive Medicine inclui em seu guia orientação para que os profissionais encorajassem seus pacientes na abertura de informação (Disponível em: <https://www.asrm.org/Guidelines/>. Acesso em: 22 abr. 2015).

10 Disponível em: <http://www.infertilitynetworkuk.com>. Acesso em: 22 jan. 2016.
} 
quando a informação é trazida na vida adulta sobre um fato desconhecido de sua história (Snowden; Snowden, 1998; Jadva et al., 2010).

Casais de mesmo sexo e mães solteiras figuram nos estudos como aqueles que se mostram mais abertos a falar sobre o fato. A ausência de um pai nesses casos antecipa o contexto de falar sobre o assunto com a criança (Stevens et al., 2003; Readings et al., 2011; Patterson, Riskind, 2010; Patterson, 2009).

Se a noção em torno do segredo nas práticas que envolvem uso de doador pode parecer menos potente ou expressar um processo de perda de valor, a manutenção do anonimato quanto à identidade do doador continuava ainda sendo debatida. As principais defesas da manutenção do anonimato na doação de material genético estavam baseadas no risco da diminuição dos doadores de material genético e na introdução do doador na privacidade da família da criança concebida (visto como um potencial desestabilizador do núcleo por desvelar segredos do casal) e da pessoa concebida na privacidade e vida da família do doador.

Os serviços médicos e responsáveis pelos bancos de sêmen temiam que a abolição do anonimato representasse uma diminuição dos doadores. Estudos indicam que a remoção do anonimato na Suécia trouxe um impacto negativo na demanda e recrutamento dos doadores de gameta (Turkmendag et al., 2008; Cook et al., 1995). Ademais, o país promoveu alterações nos métodos de recrutamento, como a recomendação de que caso o doador fosse casado houvesse o consentimento da esposa sobre a decisão. Segundo Lalos et al.(2003), os doadores passaram a ser homens na faixa etária de 34 a 40 anos, casados, com filhos, motivados pelo desejo de ajudar casais inférteis que não conseguem conceber. Anteriormente, predominava no perfil de doadores estudantes universitários que utilizavam a doação para financiar os estudos.

Argumenta-se que o novo perfil de doador é mais ético, contudo a questão de sua maior idade tem sido destacada como um problema pelas clínicas, à medida que com o tempo o volume do sêmen e a motilidade diminuem, tornando esse sêmen menos desejado na prática clínica (Turkmendag et al.,
2008; Daniels, 1998). Esse quadro tem acarretado o aumento de filas de espera para realização do procedimento de DI. Em face dessa dificuldade na obtenção de doadores, há indicações de que aumenta a procura pela aquisição de sêmen no exterior e também em países que ainda mantêm a prática do anonimato, que é o caso, por exemplo, dos Estados Unidos e da Dinamarca (Turkmendag et al., 2008; Hudson; Culley, 2011; Volkman, 2012) ${ }^{11}$.

Desde 2005, qualquer criança nascida no Reino Unido por meio de doação de gametas tem o direito legal de receber informação não identificável sobre seu doador a partir dos 16 anos, e pode acessar informação identificável (incluindo o nome completo e último endereço conhecido) a partir dos 18 anos. As informações são registradas e mantidas pela UK Human Fertility and Embriology Authority (HFEA), autoridade dedicada a licenciar e monitorar clínicas de fertilidade e pesquisas no Reino Unido envolvendo embriões humanos, e com um número de referência o jovem na idade definida pode acessar e obter informações via internet.

As primeiras manifestações visando transformar o anonimato de doadores numa questão de debate público no Reino Unido datam do final dos anos 1990, quando The Children's Society, uma entidade caritativa se manifestou pela retirada do anonimato, objetivando igualar a situação legal das crianças adotadas à daquelas concebidas por meio do uso de material genético de terceiros (Turkmendag, 2012). 0 argumento está baseado no fato de que crianças concebidas por meio de doadores anônimos têm as mesmas necessidades das adotadas e negar isso infringe seus direitos. Posteriormente, esta posição foi reforçada pela Baronesa Warnock, que conduziu o comitê responsável pelo estabelecimento das principais recomendações éticas e legais no campo da reprodução assistida, que resultou na criação da HFEA. $O$ argumento nesse contexto não só menciona o acesso à informação (igualando ao direito dos adotivos) como também afirma a importância do conhecimento sobre a herança genética para a construção da identidade (Dyer, 2002).

Os debates que se seguiram promovidos pelo

11 Desde 2002, a Dinamarca figura como uma das líderes deste “mercado”, exportando para mais de cinquenta países (Volkman, 2012, p. 295). 
Departamento de Saúde, através de uma consulta pública, e aqueles havidos no Parlamento, tomaram como parâmetro a questão do alinhamento mais próximo dos direitos dos concebidos por doação de gametas aos dos adotados, visando evitar segredos e estigmas. Outro aspecto destacado é que ir contra essa abertura de informação colocava o governo em desrespeito com a Convenção Europeia dos Direitos Humanos e a Declaração Universal dos Direitos da Criança, que estabelece o direito das crianças à informação e ao acesso sobre suas origens genéticas.

A proliferação da crença da genética na determinação de um crescente conjunto de características tem tido profunda influência nos discursos relativos à compreensão sobre saúde e doença, que se tornaram bastante genetizadas (Mamo, 2007).

A questão do acesso das pessoas adotadas sobre sua história de vida e sobre os efeitos danosos ao seu bem-estar, e identidade decorrente do segredo sobre seus pais de nascimento e das condições da sua trajetória têm sido bem explorados pela literatura (Fonseca, 1995, 2009; Brodzinsky et al., 2012; Marre et al., 2004). A manutenção do segredo sobre a adoção foi ruindo, particularmente, no pós-guerra quando sobressaiu o princípio do "bem-estar dos filhos". No Reino Unido, a lei de adoção reconhece o direito da criança em acessar qualquer informação disponível, a menos que haja decisão legal que a impeça. Destaca-se que a Inglaterra foi o primeiro país a tomar esta atitude de abertura (Turkmendag, 2008; Fonseca, 2010).

Contudo, essa posição de abertura não é hegemônica. A adoção plena e premissa do sigilo total emergiram nos Estados Unidos (EUA) em torno de 1960, quando a adoção foi baseada numa réplica da reprodução biológica, sendo importante afastar a memória dos pais biológicos. A premissa de sigilo total quanto às famílias de origem é algo valorizado e visto como necessário, objetivando promover o bem-estar dos adotados (Fonseca, 2009). Chavear os arquivos está ligado aos estereótipos negativos construídos sobre a mãe de nascimento (como abandonante), ao medo da "concorrência" pelo afeto da criança e em buscar imitar o "natural", consanguíneo. Assim, a adoção figuraria como se aquela criança tivesse nascido naquela família. Fonseca (2009) considera que embora a preocupação com a busca das origens genéticas entre os adotados apareça no Brasil, ela tem permanecido ausente no discurso oficial de adoção no Brasil e também na América Latina, com exceção da Argentina (em razão da sua particularidade histórica) ${ }^{12}$.

A posição de igualar a adoção à doação de gametas no debate inglês, por corresponderem a processos similares, nesse sentido, é discutível. A adoção envolve um processo em que há uma teia de relações prévias (família) à adoção; na concepção com doador busca-se criar uma criança para estabelecer uma família (Haimes, 1988; Volkman, 2012). Na reprodução assistida, em geral ${ }^{13}$, uma criança concebida pode possuir vinculação biológica/genética com ao menos um dos integrantes do casal, ao passo que na adoção não há vínculo com nenhum deles. Informações sobre o histórico médico do doador são guardadas pela autoridade médica e a criança adotada, em regra, não dispõe desses registros.

Outro aspecto a ser mencionado é a diferença entre ter acesso às circunstâncias e fatos relativos à sua origem e a importância de conhecer a identidade do doador. A ênfase na importância do conhecimento da história genética para a constituição da identidade é um argumento ancorado num núcleo mais abrangente relativo às nossas representações sobre parentesco e filiação. Salem (1995), discutindo o princípio do anonimato, observa que a interpretação sobre a noção de filiação na Inglaterra indica que a "veracidade" biológica apresenta maior preeminência. A força desse fato pode ser considerada no reconhecimento de que, inicialmente, a autoridade que legislava sobre a reprodução assistida considerava a criança obtida por meio de ID como ilegítima, já que o critério biológico é visto como fundamento da presunção da paternidade e o marido da mãe possui um parentesco biológico com a criança (Strathern, 1982). No debate o peso dessa posição pode

${ }_{12}$ No Brasil o adotado tem direito a conhecer sua origem biológica após completar 18 anos por meio do acesso à Justiça (Fonseca, 2010).

${ }_{13}$ Uso a expressão "em geral” porque, por meio das tecnologias reprodutivas, a criança nascida poderia não ter qualquer vínculo genético com a mulher que a gesta e o(a) parceiro(a) desta. 
ser observado na defesa pela associação britânica para adoção, British Association for Adoption and Fostering (BAAF), de que o doador fosse incluído nos registros de nascimento da criança, advogando isso como um princípio moral e considerando que não fazê-lo implicava transformar a criança nascida em uma vítima dos seus pais (Turkmendag, 2012).

Nesse contexto, é importante considerar as vozes dissonantes quanto à abolição do princípio do anonimato. A supressão do anonimato encontrou profundas resistências entre representantes da comunidade médica (British Fertility Society/BFS, Royal College of Obstetricians and Gynaecologists e British Medical Association), baseados no impacto dessa medida na disponibilidade de doadores e correspondente aumento dos custos envolvidos nos procedimentos, podendo levar pacientes a procurar tratamentos no exterior (Turkmendag, 2012). Importa considerar que a autoridade médica tinha sido, até recentemente, a grande mantenedora da cultura do segredo, que envolve a doação de gametas já que é a depositária das informações sobre a identidade do doador e quem deve guardar as informações, tendo por princípio potenciais riscos à saúde.

Apesar da força deste grupo no contexto da discussão em foco, sua posição foi derrotada. A ênfase dada pela biomedicina na importância dos genes, seja sob a perspectiva de doenças hereditárias a que podemos estar sujeitos, seja com relação a procedimentos e atitudes indicadas como importantes para a manutenção da saúde, representa um discurso bastante potente na atualidade. Outro grupo mencionado como uma voz dissonante nesse debate é aquele representado pelos "futuros pais", casais que pretendiam futuramente utilizar a técnica para obtenção de um bebê e estavam em lista de espera para uso de doação de gametas ou tinham planos de o fazê-lo e seriam, significativamente, afetados pela mudança na legislação. Segundo Turkmendag (2008), sua posição não emergiu com significativa força no debate em razão dos receios de uma exposição pública da sua situação (infertilidade). Sua posição foi levantada a partir do grupo on-line mais ativo de apoio a pais e futuros pais interessados em serviços de reprodução assistida no Reino Unido. A consulta conduzida por Turkmendag (2008), em fóruns de discussão, no período de julho de 2005 a abril de 2006, indicava haver muita resis- tência, alegando como problemas a diminuição da disponibilidade de doadores e a discordância com o fim do anonimato.

Abusca pelas "verdadeiras origens" ganhou status de necessidade universal e no discurso contemporâneo estudos indicam a possibilidade da ocorrência de uma confusão genealógica ou quebra da narrativa de si (genealogical bewilderment, the broken narrative) caso essa informação não seja revelada (Lifton, 1994; Volkman, 2012). Contudo, essa visão não é hegemônica, já que nem todos se sentem tocados pelo apelo do sangue na construção de sua identidade.

Nesse contexto de busca pelas origens não podemos minimizar o potencial interesse do mercado biomédico. Volkman (2012), em estudo enfocando a busca de irmãos de crianças chinesas adotadas por famílias nos Estados Unidos pela testagem de DNA, indica o quanto essas buscas podem representar para a expansão do mercado de testagens. No caso da retirada do anonimato, a decisão parece criar condições para a ampliação do mercado de células genéticas, na medida em que tem havido um aumento na procura em países como Estados Unidos e Dinamarca.

Mas, igualmente, emergem com força as facilidades operadas pela Internet na possibilidade de buscar partes perdidas da história genética de pessoas adotadas ou concebidas por meio do acesso a material genético de terceiros como a literatura vem demonstrando, instigando uma busca pelo desconhecido (Volkman, 2012; Daniels, 2007; Jadva et al., 2010; Beeson et al., 2011). Nesse sentido, Volkman nos provoca trazendo a ideia de que a ênfase nessa "necessidade genética" talvez esteja ligada a uma busca identitária em um mundo cada vez mais marcado pela heterogeneidade.

\section{Considerações finais}

Qual é a situação do Brasil nesse contexto? Há reverberação desse debate no país? No Brasil, o doador de material genético permanece anônimo, de acordo com a Resolução do Conselho Federal de Medicina (2013). A resolução médica estabelece regras distintas quanto ao anonimato, sendo este mantido para o material genético e não para a gestação substituta, hierarquizando os "tipos de cessão" e indicando a primazia do genético (Luna, 2007). Como observam Vasconcelos et 
al.(2014), ter conhecimento sobre a origem genética é ainda questão polêmica no país porque isso romperia com demais normativas existentes quanto ao sigilo, confidencialidade médica e autonomia dos sujeitos.

Em termos modelares, um doador entrega seu sêmen em um dos dois bancos existentes no país (ambos em São Paulo), e este distribui o material genético congelado por meio de solicitação de clínicas médicas. Uma lista com as características fenotípicas disponíveis nos bancos é consultada pela clínica com a orientação (segundo a norma médica) de que o médico busque a compatibilização do sêmen solicitado com as características do casal/ pessoa solteira que demanda. Estudos parecem indicar que não há uma preocupação ou interesse entre casais heterossexuais e casais de mulheres, que usam as tecnologias pela abertura do anonimato (Machin; Couto, 2014; Corrêa, 2012). Profissionais médicos igualmente observam que o anonimato é fundamental, alegando as mesmas preocupações apresentadas no debate britânico - risco da diminuição de doadores em razão da abertura da identidade do doador (Luna, 2007; Corrêa, 2012; Machin, 2014).

Outra situação que tangencia a abertura do anonimato no âmbito da doação de sêmen é aquela relativa aos casos de adoção. A revisão da Lei de Adoção no Brasil, que permite o acesso dos adotados a todas as informações disponíveis sobre sua história, data de 2009. No entanto, como observa Fonseca (2010), há muita dificuldade em fazer esses direitos serem efetivados, uma vez que o adotado precisa vencer a burocracia de várias instituições - hospital, cartório, tribunal, para ter acesso a informações sobre sua história. Os mecanismos procedimentais são centrais no estabelecimento de fato desses direitos. A possibilidade de acessar os dados por meio de um número de registro relativo ao doador e pela web (caso do modelo inglês) mantém a privacidade de quem faz a busca e traz efetividade quanto ao seu resultado.

Concordo com Fonseca (2009) quanto ao fato de que a legislação deve ser vista como uma tecnologia de governança que se estabelece moldando subjetividades individuais (Rose, 2006). E, nesse sentido, por meio das definições legais quanto à abolição do anonimato de doadores e fim do sigilo quanto às informações de genitores de adotados, constroem- -se relações, identidades e ampliam-se relações de parentesco e família.

No entanto, a legislação pode não mudar atitudes. Considerando a situação da Suécia, primeiro país a abolir o anonimato, estudos indicam não ter havido uma abertura significativa na posição dos pais em falar sobre a concepção com uso de doador para os filhos (Gottlieb et al,. 200o). Gottlieb estudou a atitude dos pais perante o fim do anonimato e indica que somente $11 \%$ deles falaram para o filho concebido sobre o processo. A principal alegação referida foi "desnecessário" e "receio de ferir a criança”. O estudo realizado por Lalos et al. (2007), conduzido entre famílias que fizeram uso de doador de sêmen, revelou que $61 \%$ falaram ao filho sobre o processo de concepção, mas $61 \%$ não abordaram a possibilidade de o doador ser identificado.

Há várias questões com relação ao momento adequado de se falar e a maneira como essas histórias podem ser reveladas, conforme Blake (et al, 2010). Segundo esse estudo realizado com famílias no Reino Unido concebidas via inseminação com doador, a maioria dos pais que resolve abrir a informação o faz quando a criança tem entre 4 e 5 anos e entre 7 e 8 anos de idade. Na maioria dos casos, a abertura foi feita pela mãe num processo de construção de narrativa em que mencionam parte do corpo, que não funciona impedindo a chegada de uma criança de forma "natural". o processo é considerado pelos pais/mães difícil e doloroso, havendo receio de ser rejeitado e dúvidas quanto a estar usando a história e a linguagem adequada para aquela idade específica. Há indicação de que a reação das crianças é de neutralidade ou recebem bem a história.

Se as relações de sangue e a genética confere inteligibilidade ao princípio do anonimato, é certo que sua abolição demonstra a importância da genetização da identidade pessoal e do parentesco (Finkler, 200o). Se no debate que vem desde os anos 1990 a força dos laços naturais e da natureza imprimiu o anonimato como regra, na atualidade para muitos países - o Reino Unido em particular nessa trajetória - confirma-se a valorização das relações de sangue na conformação da identidade pessoal.

Estaríamos diante de uma subversão às regras anteriormente definidas no campo reprodutivo, que 
através do segredo e anonimato envolvendo o uso de material genético de terceiros, buscavam camuflar a intervenção humana? Os arranjos socialmente estabelecidos pelo acesso à medicina reprodutiva visando "imitar a natureza" agora precisam ser revelados?

Assim, pode-se considerar que, se por um lado cada vez mais se afirma uma ordem reprodutiva baseada em "escolhas" e direitos individuais, ter filhos, quando ter filhos e como ter filhos assiste-se igualmente a uma genetização do ser humano e de suas relações familiares.

Regras de filiação, maternidade e paternidade falam de códigos, categorias de pensamento que operam simbolicamente na demarcação de quem são nossos parentes, nossa família. A medicina reprodutiva ao ajudar a conceber um bebê para aqueles que não podem reproduzir usando seu próprio material genético e necessitam do apoio de terceiros, opera por meio de três dispositivos: segredo do casal que usa a técnica, anonimato do doador do material genético e tentativa de compatibilizar as características do doador com as do casal receptor (Salem, 1995). Ao abolir o segredo e o anonimato há um rompimento com dois dispositivos, que proporcionavam naturalizar os arranjos socialmente estabelecidos. Se por um lado esta situação denota a primazia dos laços biológicos sobre os sociais ou da noção de natureza sobre aquela de cultura, por outro, igualmente traz um rompimento com a visão essencialista de que a filiação e também o cuidado estão ligados a um só casal (Fonseca, 2010). O desenvolvimento pode ser compreendido como algo amplo e que está além do casal, como exemplos de outras culturas nos têm demonstrado.

\section{Referências}

ALMELING, R. Gender and the value of bodily goods: commodification in egg and sperm donation. Law and Contemporary Problems, Durham, v. 72, n. 37, p. 37-58, 2009.

BEESON, D. R. et al. Offspring searching for their sperm donors: how family type shapes the process. Human Reproduction, Oxford, v. 26, n. 9, p. 2415-2424, 2011.

BLAKE, L. et al. 'Daddy ran out of tadpoles': how parents tell their children that they are donor conceived, and what their 7-years-olds understand. Human Reproduction, Oxford, v. 25, n. 10, p. 2527-2534, 2010.

BLYTH, E.; FARRAND, A. Anonymity in donorassisted conception and the UN Convention on the rights of the child. The International Journal of Children's Rights, London, v. 12, n. 2, p. 89-104, 2004. BRODZINSKY, D. M.; PERTMAN, A. Adoption by lesbian and gay men: a new dimension in family diversity. Oxford: Oxford University Press, 2012.

CAMERON, A. et al. De-anonymising sperm donors in Canada: some doubts and directions. Canadian Journal of Family Law, Vancouver, v. 26, p. 95-148, maio. 2010.

CFM - CONSELHO FEDERAL DE MEDICINA. Resolução CFM no. 2013/2013. Brasília, DF, 2013. Disponível em: <http://www.portalmedico.org.br/ resolucoes/CFM/2013/2013_2013.pdf >. Acesso em: 4 out. 2014 .

COOK, R.; GOLOMBOK, S. A survey of semen donation: Phase II, the view of donor. Human Reproduction, Oxford, v. 10, n. 4, p. 951-959, 1995.

CORREA, M. E. C. Duas mães? Mulheres lésbicas e maternidade. 2012. Tese (Doutorado em Ciências) - Faculdade de Saúde Pública da Universidade de São Paulo, São Paulo, 2012.

DANIELS, K.; HAIMES, E. (Org.). Donor insemination: international social science perspectives. Cambridge: Cambridge University Press, 1998.

DANIELS, C. R. Exposing men: the science and politics of male reproduction. Oxford: Oxford University Press, 2006.

DANIELS, K. Donor gametes: anonymous or identified? Best Practice \& Research Clinical Obstetrics and Gynaecology, London, v. 21, n. 1, p. 113-128, 2007.

DANIELS, K. et al. Parental information sharing with donor insemination conceived offspring: a follow-up study. Human Reproduction, Oxford, v. 24, n. 5, p. 1099-1105, 2009.

DYER, C. Pressure increases on UK government to remove anonymity from sperm donors. British Medical Journal, London, v. 324, n. 7348, p. 1237, 2002. 
FINKLER, K. Experiencing the New Genetics: family and kinship on the medical frontier. Philadephia: University of Pennsylvania Press, 2000.

FONSECA, C. Caminhos da adoção. São Paulo: Cortez, 1995.

FONSECA, C. Abandono, adoção e anonimato: questões de moralidade materna suscitadas pelas propostas legais de "parto anônimo". Sexualidad, salud y sociedade. Revista Latinoamericana, Rio de Janeiro, n. 1, p. 30-62, jan. 2009.

FONSECA, C. O direito às origens: segredo e desigualdade no controle de informações sobre a identidade pessoal. Revista de Antropologia, São Paulo, v. 53, n. 2, p. 493-526, 2010.

FONSECA, C. Law, technology and gender relations: following the path of DNA paternity tests in Brazil. In: BROWNER, C. H.; SARGENT, C. F. (Ed.). Reproduction, globalization, and the State: new theoretical and ethnographic perspectives. Durham; London: Duke University Press, 2011. p. 138-153.

FRITH, L. Gamete donation and anonymity: the ethical and legal debate. Human Reproduction, Oxford, v. 16, n. 5, p. 818-824, 2001.

GOLOMBOK, S. Research on gay and lesbian parenting: an historical perspective across 30 years. Journal of GLBT Family Studies, v. 3, n. 2-3, 2007. Disponível em: <http://www.tandfonline. com/doi/abs/10.130o/J461vo3no2_a?journalCode= wgfs2o>. Acesso em: 22 jan. 2016.

GOTTLIEB, C.; LALOS, O.; LINDBLAD, F.

Disclosure of donor insemination to the child: the impact on Swedish legislation on couples' attitudes. Human Reproduction, Oxford, v. 15, n. 9, p. 2052-2056, 2000.

HAIMES, E. The making of 'the DI child': changing representations of people conceived through donor insemination. In: DANIELS, K.; HAIMES, E. (Org.). Donor insemination: international social science perspectives. Cambridge: Cambridge University Press, 1998.

HUDSON, N.; CULLEY, L. Assisted reproductive travel: UK patient trajectories. Reproductive BioMedicine Online, Oxford, v. 23, n. 5, p. 573-581, 2011.
JADVA, V. et al. Experiences of offspring searching for and contacting their donor siblings and donor. Reproductive BioMedicine Online, Oxford, v. 20, n. 4, p. 523-532, 2010.

JOHNS, R. Abolishing anonymity: a rights-based approach to evaluating anonymous sperm donation. UCLA Women's Law Journal, Los Angeles, v. 20, n. 2, p. 111-136, 2013.

KARPEL, M. A. Family secrets: I. Conceptual and ethical issues in the relational context. II. Ethical and practical considerations in therapeutic management. Family Process, Malden, v. 19, n. 3 , p. 295-306, 1980.

LALOS, A. et al. Recruitment and motivation of semen providers in Sweden. Human Reproduction, Oxford, v. 18, n. 1, p. 212-216, 2003.

LALOS, A.; GOTTLIEB, C.; LALOS, O. Legislated right for donor-insemination children to know their genetic origin: a study of parental thinking. Human Reproduction, Oxford, v. 22, n. 6, p. 1759-1768, 2007.

LASKER, J. N. The users of donor insemination. In: DANIELS, K.; HAIMES, E. (Ed.). Donor insemination: international social science perspectives. Cambridge: Cambridge University Press, 1998.

LIFTON, B. J. Journey of the adopted self: a quest for wholeness. New York: Basic Books, 1994.

LUNA, N. Provetas e clones: uma antropologia das novas tecnologias reprodutivas. Rio de Janeiro: Fiocruz, 2007.

MACHIN, R. Sharing motherhood in lesbian reproductive practices. BioSocieties, London, v. 9, n. 1, p. 42-59, 2014.

MACHIN, R.; COUTO, M. T. "Fazendo a escolha certa": tecnologias reprodutivas, práticas lésbicas e uso de bancos de sêmen. Physis, Revista de Saúde Coletiva, Rio de Janeiro, v. 24, n. 4, p. 12551274, 2014.

MAMO, L. Queering reproduction: achieving pregnancy in the age of technoscience. Durham; London: Duke University Press, 2007.

MARRE, D.; BESTARD, J. Sobre la adopción y otras formas de constituir famílias: a modo de introducción. In: MARRE, D.; BESTARD, J. 
(Ed.). La adopción y el acogimiento: presente y perspectivas. Barcelona: Publicacions I Editions de La Universitat de Barcelona, 2004. p. 17-72.

MOHR, S. Beyond motivation: on what it means to be a sperm donor in Denmark. Anthropology \& Medicine, London, v. 21, n. 2, p. 162-173, 2014.

NOVAES, S. Giving, receiving, repaying: gamete donors and donor policies in reproductive medicine. International Journal of Technology Assessment in Health Care, Helsinki, v. 5, n. 4, p. 639-657, 1989.

ORENSTEIN, P. Looking for a DONOR to call DAD. 1995. The New York Times Magazine, [online].

Disponível em: <http:/www.nytimes.com/1995/o6/18/ magazine/looking-for-a-donor-to-call-dad.

html?pagewanted=all>. Acesso em: 22 jan. 2016.

PATTERSON, C. J. Children of lesbian and gay parents: psychology, law and policy. American Psychologist, Washington, DC, p. 727-735, nov. 2009.

PATTERSON, C. J.; RISKIND, R. G. To be a parent: issues in family formation among gay and lesbian adults. Journal of GLBT Family Studies, New York, v. 6, n. 2, p. 326-340, 2010.

READINGS, J. et al. Secrecy, disclosure and everything in between: decisions of parents of children conceived by donor insemination, egg donation and surrogacy. Reproductive BioMedicine Online, Oxford, v. 22, n. 5, p. 485-495, 2011.

ROSE, N. Governing the soul: the shaping of the private self. London: Free Association Books, 2006.

SALEM, T. O princípio do anonimato na Inseminação Artificial com Doador (IAD). Physis - Revista de Saúde Coletiva, Rio de Janeiro, v. 5, n. 1, p. 33-68, 1995.

SCHEIB, J. E.; RUBY, A. Contact among families who share the same sperm donor. Fertility and Sterility, Birmingham, v. 90, n. 1, p. 33-42, 2008.

SCHMIDT, M.; MOORE, L. J. Constructing a "good catch”, picking a winner. In: FLOYD-DAVIS, R.; DUMIT, J. (Ed.). Cyborg babies: from techno-sex to techno-tots. New York; London: Routledge, 1998. p. 21-39.

SNOWDEN, R.; SNOWDEN, E. Families created through donor insemination. In: DANIELS, K.; HAIMES, E. (Ed.). Donor insemination: international social science perspectives. Cambridge: Cambridge University Press, 1998.

SÖDERSTRÖM-ANTTILA, V. et al. Increasing openness in oocyte donation families regarding disclosure over 15 years. Human Reproduction, Oxford, v. 25, n. 10. p. 2535-2542, 2010.

SOROSKY, A. D. et al. The adoption triangle: sealed or open records: how they affect adoptees, birth parents and adoptive parents. New York: Anchor Press-Doubleday, 1984.

STEVENS, M. et al. Openness in lesbian-mother families regarding mother's sexual orientation and child's conception by donor insemination. Journal of reproductive and infant psychology, Bristol, v. 21, n. 4, p. 347-362, 2003.

STRATHERN, M. The meaning of assisted kinship. In: STACEY, M. (Ed.). Changing human reproduction. London: Sage, 1982. p. 119-47.

TURKMENDAG, I. The donor-conceived child's "right to personal identity": the public debate on donor anonymity in the United Kingdom. Journal of Law and Society, Nottingham, v. 39, n. 1, p. 283-310, 2012.

TURKMENDAG, I. et al. The removal of donor anonymity in the UK: the silencing of claims by wouldbe parents. International Journal of Law, Policy and the Family, Oxford, v. 22, n. 3, p. 283-310, 2008.

VASCONCELOS, C. et al. Direito ao conhecimento da origem biológica na reprodução humana assistida: reflexões bioéticas e jurídicas. Bioética, Brasília, DF, v. 22, n. 3, p. 509-518, 2014.

VOLKMAN, T. A. Seeking sisters: twinship and kinship in an age of internet miracles and DNA Technologies. In: BRIGGS, L.; MARRE, D. (Ed.). International adoption: global inequalities and the circulation of children. New York; London: New York University Press, 2012. p. 283-302.

WARNOCK REPORT. Report of the Committee of Inquiry into Human Fertilisation and Embryology. London: Department of Health \& Social Security, 1984.

Recebido: 29/04/2015

Reapresentado: 03/09/2015

Aprovado: 04/09/2015 